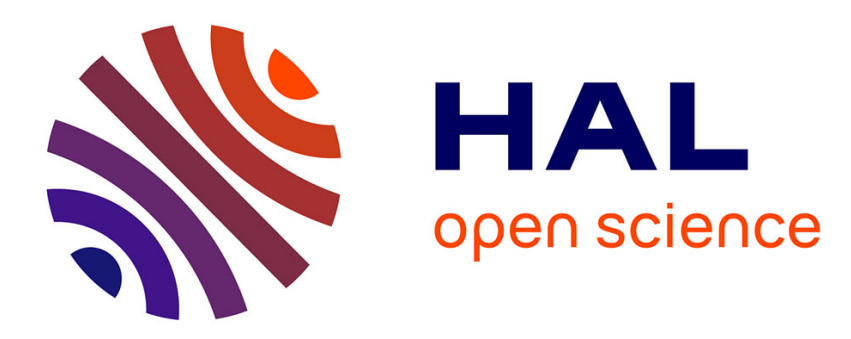

\title{
Long-Term Life of Ni/Cu Bellows: Effect of Diffusion on Thermomechanical Properties
}

Olivier Arnould, François Hild

\section{To cite this version:}

Olivier Arnould, François Hild. Long-Term Life of Ni/Cu Bellows: Effect of Diffusion on Thermomechanical Properties. Defect and Diffusion Forum, 2002, 203-205, pp.61-80. 10.4028/www.scientific.net/DDF.203-205.61 . hal-00002921

\section{HAL Id: hal-00002921 \\ https://hal.science/hal-00002921}

Submitted on 21 Sep 2004

HAL is a multi-disciplinary open access archive for the deposit and dissemination of scientific research documents, whether they are published or not. The documents may come from teaching and research institutions in France or abroad, or from public or private research centers.
L'archive ouverte pluridisciplinaire HAL, est destinée au dépôt et à la diffusion de documents scientifiques de niveau recherche, publiés ou non, émanant des établissements d'enseignement et de recherche français ou étrangers, des laboratoires publics ou privés. 


\title{
Long-Term Life of Ni/Cu Bellows: Effect of Diffusion on Thermomechanical Properties
}

\author{
Olivier Arnould ${ }^{\star}$ and François Hild \\ LMT-Cachan, ENS de Cachan / CNRS-UMR 8535 / University Paris 6 \\ 61, av. du Président Wilson, F-94235 Cachan, France. \\ Ph. +33 (0)1474022 25 Fax +33 (0)147402240
}

Keywords: ageing, diffusion, grain growth, mechanical behaviour, mechanical loading, couplings, homogenisation.

\begin{abstract}
The aim of this paper is to discuss different couplings between diffusion, recrystallisation/grain growth, strain/stress, heat transfer and thermo-mechanical behaviour of metallic materials. The understanding of these different physical phenomena is needed to predict the long-term life of mechanical parts in components. Some results are presented and further studies are suggested to improve the evaluation of the (inter)diffusion and recrystallisation parameters in fine-grained electroplated Ni/Cu materials. To illustrate the coupling between elasticity and diffusion, classical results in homogenisation consistent with the main diffusion regime are used to predict the change in elastic moduli with time.
\end{abstract}

\section{Introduction}

This paper is a more detailed presentation of a study on ageing that has been introduced in Ref. [1]. It deals with a high precision pressure sensor that uses bellows to convert a pressure difference into a displacement (Fig. 1a). The high precision and airtightness of bellows require to make them as a $\mathrm{Ni} / \mathrm{Cu} / \mathrm{Ni}$ layered material (overall thickness $\sim 100 \mu \mathrm{m}$ ) obtained by an electrodeposition process on an aluminium mandrel that is dissolved in a potassium hydroxide bath. Nickel deposits (Fig. 1b) have a fine columnar structure with submicrometre to micrometre grains joined in colonies delimited by crevices surrounding them and inducing porosities [2]. Alone, nickel cannot provide the required airtightness but possesses the needed stiffness. Conversely, copper deposits as a continuous multilayer that is able to prevent (helium) diffusion through the thickness. Consequently, a copper layer (thickness $\sim 3 \mu \mathrm{m}$ ) is inserted between two layers of nickel. This configuration allows for the minimisation of the 'softening' effect of copper on the mechanical behaviour of bellows since bending is the predominant loading pattern.

Such components are expected to stay in service for many decades, thus, the ageing mode(s) of the material have to be known. The study of the main energies available in this configuration (from which the driving forces are derived) allows one to list the ageing modes that may happen. Numerous ageing modes are possible and must be investigated but the most important ones for this configuration seem to be caused, first, by the chemical gradient that gives rise to $\mathrm{Ni} / \mathrm{Cu}$ diffusion and, second, by the unstable microstructure that leads to recrystallisation (or more likely grain growth).

Consequently, the thermo-mechanical behaviour of bellows will change with time and the determination of the diffusion coefficients in this case enables one to predict stiffness (i.e., elasticity) changes induced by diffusion whereas grain growth can cause some change in the plastic behaviour for example. The paper first focuses on a presentation of the couplings that

\footnotetext{
^ to whom correspondence should be addressed. E-mail: arnould@lmt.ens-cachan.fr
} 


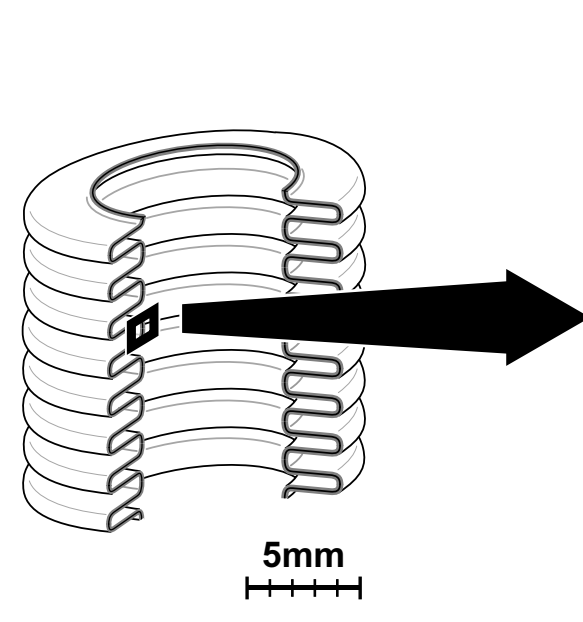

(a)

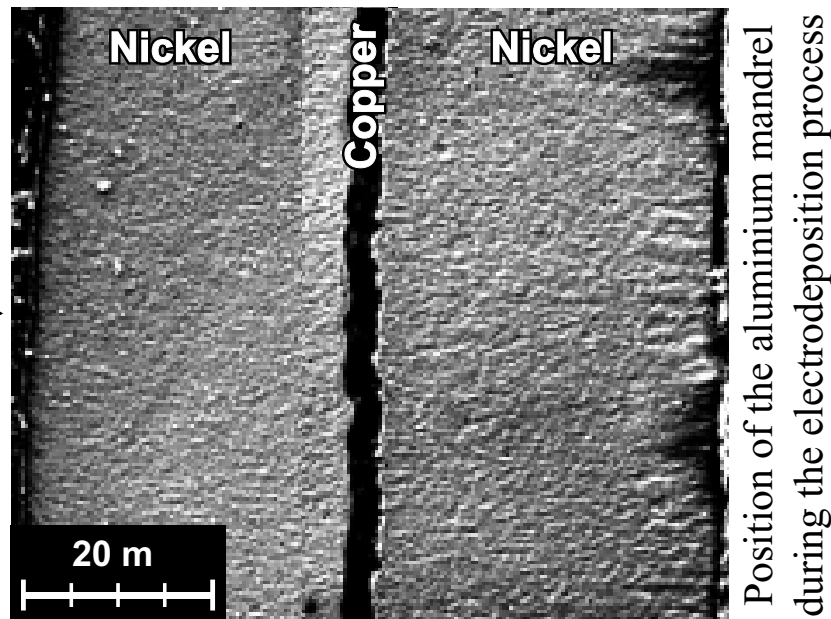

(b)

Fig. 1. a) General view of electroplated bellows. b) Electron micrograph of a cross-section obtained in an SEM after chemical etching [2]. Note the multilayered material and the fine columnar microstructure of the nickel layers.

can be expected between mechanical properties and loadings, heat transfer, (inter)diffusion and grain growth, and some ways of modelling the different interactions. Then, practical studies of diffusion and a first estimate of the associated coefficients are performed for moderate temperatures. This leads us to suggest some further improvements in the diffusion curves treatment since grain growth and the diffusion kinetics can change. Finally, homogenisation techniques in elasticity allow us to evaluate the change of the thermo-mechanical properties of the effective material with time.

\section{Thermo-mechanical, diffusion and recrystallisation couplings}

The different couplings of interest are presented in Fig. 2. The linear behaviour of materials is now well known, thus the thermo-elastic couplings can be studied with a classical formulation, which is based on the expression of thermodynamic potentials and the derived state laws [3]. For example, the second order thermal expansion tensor, $\underline{\underline{\alpha}}$, has been evaluated at a submillimetre scale by digital image correlation $[4,5]$. A CCD camera is used with a long-distance microscope. Images are taken at each temperature step and the intercorrelation between the considered image and the initial one (at room temperature) allows one to determine the inplane displacement field. The isotropy of the coefficient of thermal expansion and the associated values are determined. In the present case, these coefficients have been obtained on the surface of the bellows. The behaviour is essentially isotropic and corresponds mainly to the electrodeposited nickel contribution (Fig. 3). The average value of the coefficient is higher than for bulk nickel and seems to be closer to bulk copper when the temperature $T$ increases. This could be explained by the copper layer that is inside the nickel layers. However, the copper layer should not 'impose' its deformation as its thickness is too small compared to that of nickel (see Fig. 1b). Furthermore, the Young's modulus of copper is less than that of nickel. Therefore, this change in the thermal expansion coefficient may be due to the particular microstructure of the nickel electrodeposits.

This macroscopic thermal expansion coefficient, such as the components of the stiffness tensor (i.e., elastic moduli $E_{i j}$ and Poisson's ratios $\nu_{i j}$ ), and the second order thermal conductivity 


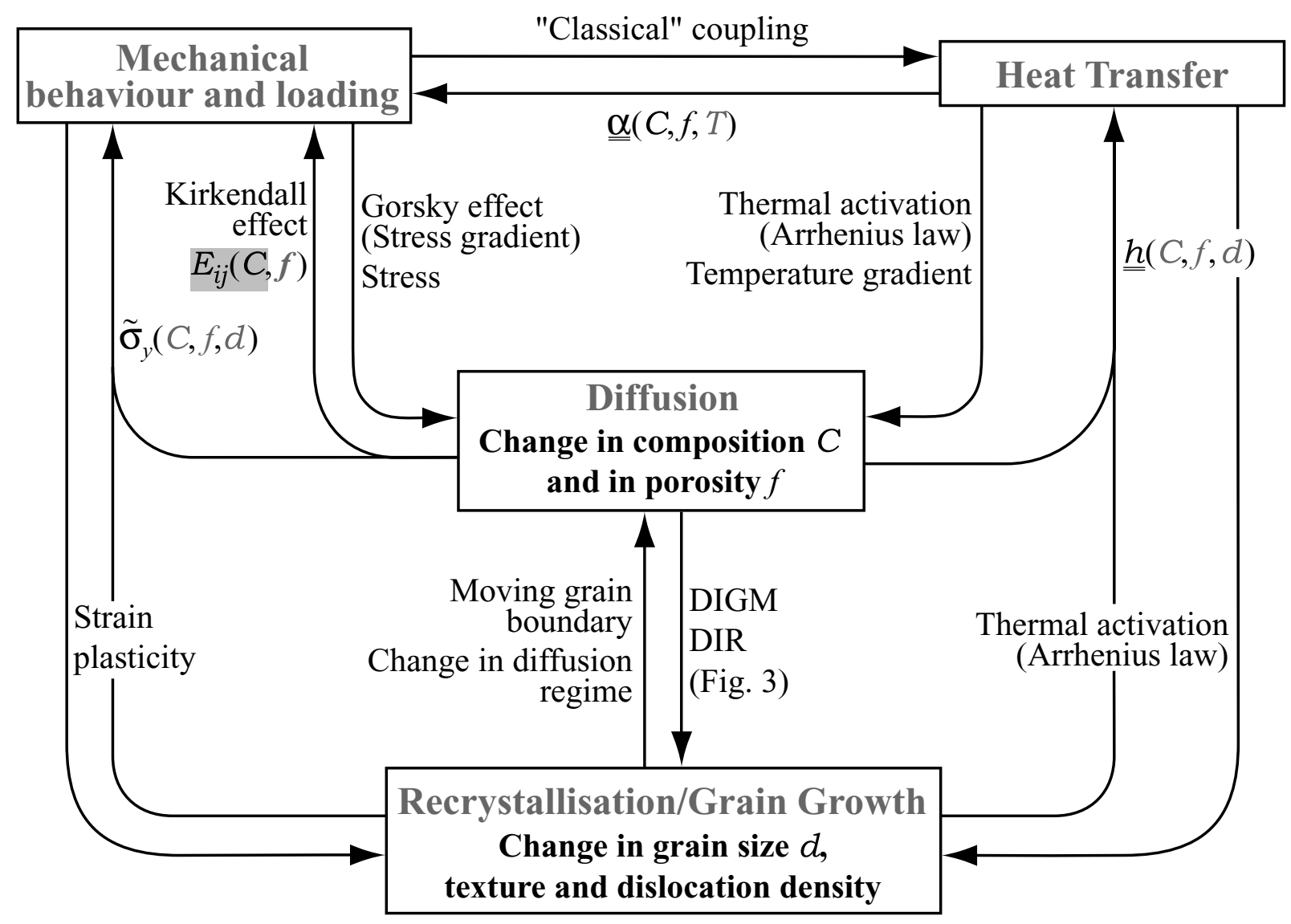

Fig. 2. Overall view of the assumed thermo-mechanical, diffusion and recrystallisation couplings. DIGM stands for 'Diffusion-Induced Grain Migration', DIR for 'Diffusion-Induced Recrystallisation', $\underline{\underline{\alpha}}$ is the thermal expansion second order tensor, $\underline{\underline{h}}$ the heat conductivity tensor, $E_{i j}$ the components of the stiffness tensor and $\tilde{\sigma}_{y}$ the yield stress and its possible anisotropy. The present study is mainly focused on the determination of the change of $E_{i j}$ with the concentration $C$.

tensor $\underline{\underline{h}}$, depend on the local (i.e., microscopic) concentration in nickel and copper $C(\underline{x})$. This can be obtained by homogenisation techniques with the same approach for all these coefficients as those presented in Section 4 for the stiffness. Therefore, the change of these material parameters with time depends on the concentration profile that will be determined by the diffusion coefficients. It is important to note here that the (average) grain size, $d$, and texture can have a non negligible influence on the previous parameters. First, the homogenisation techniques used herein assume that the representative pattern is small compared with the structure length scale (i.e., layers thicknesses) and loading gradients. If these conditions are not fulfilled, boundary effects have to be accounted for and other models must be used. Lastly, the global pattern (i.e., statistical distribution) can affect the macroscopic behaviour, especially for the thermal conductivity (see Section 4).

The effect of temperature on diffusion and grain growth is modelled by an Arrhenius law as a thermally-activated process. Moreover, a temperature gradient can affect the atomic diffusion flux as it will be described below. The effect of diffusion on the mechanical loading arises from the difference between the different diffusing species in the product $\bar{V}_{i} M_{i}$, where $\bar{V}_{i}$ stands for the molar (or atomic) volume of the species $i$, and $M_{i}$ its mobility (linked to the intrinsic diffusion coefficient $D_{i}$ ). This effect induces an imbalance in the volume transport and, in a binary diffusion couple, the side containing the species with the lower product will shrink 


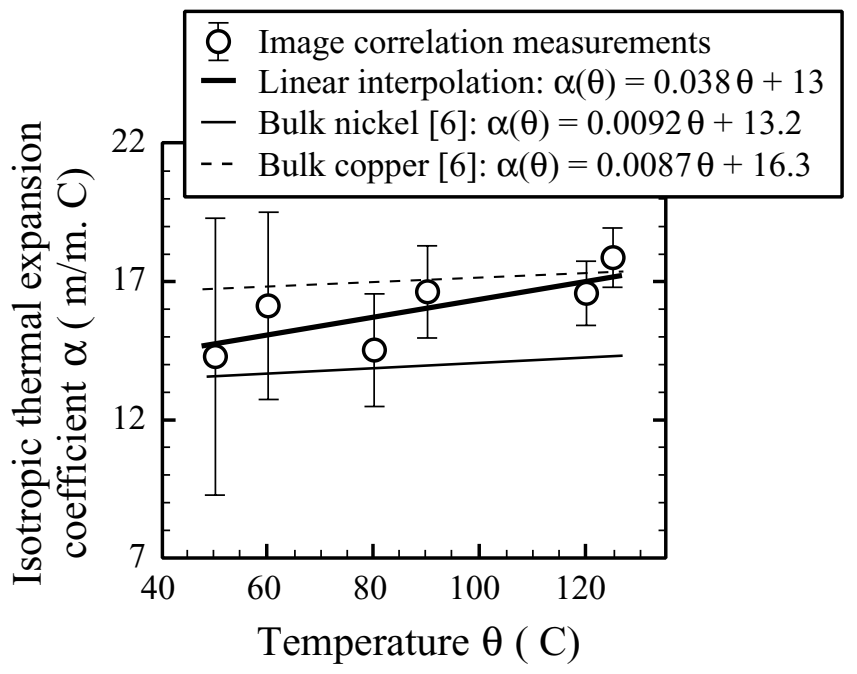

Fig. 3. Image correlation measurements of the (nearly) isotropic thermal expansion coefficient of electroplated $\mathrm{Ni} / \mathrm{Cu}$ multilayers (reference temperature: $20^{\circ} \mathrm{C}$ ). Comparisons with bulk nickel and copper coefficients. The scatter (i.e., the error bars) is mainly due to the accuracy in displacement measurement combined with the fact that, the lower the temperature, the lower the dilatational displacements.

whereas the other one will expand. The corresponding stress-free strain can be expressed by $[7,8,9]$

$$
\underline{\underline{\underline{\varepsilon}}}=\frac{1}{3} \operatorname{div}\left(\bar{V}_{A} J_{A}^{\prime}+\bar{V}_{B} J_{B}^{\prime}\right) \underline{\underline{1}},
$$

where $J_{i}^{\prime}$ is the flux of the species $i$ in the lattice frame $\left(J_{i}=J_{i}^{\prime}+v_{\mathrm{K}}(\underline{x}) C_{i}\right.$, with $J_{i}$ the flux in the laboratory frame and $v_{\mathrm{K}}$ the velocity of the lattice frame relative to the laboratory frame usually measured by Kirkendall markers). The strain in Eq. (1) induces stresses that can be visualised by the bending of thin-sheet diffusion couples [10, 11, 9] even for a $\mathrm{Ni} / \mathrm{Cu}$ couple [12]. If the stresses relax faster than the diffusion characteristic time and completely, the convective transport (i.e., plastic flow) that occurs leads to the 'classical' Kirkendall effect (i.e., the displacement of the Kirkendall plane is proportional to the square root of time $[13,14,15,16])$ and the classical Darken model is valid $[17,7]$. In the opposite case, the stress developping slows down diffusion (see Eq. (3)) and its relaxation can mainly control diffusion. This case corresponds to the NernstPlanck limit (with approximately no marker displacement [8]). Diffusion kinetics in these two extreme cases are completely different and all the possible cases in the transition regime can be obtained by varying the layer thicknesses in compositionally modulated multilayered diffusion couples [8, 18]. Moreover, the Kirkendall effect implies a diffusion of vacancies in the direction opposite to the net flux of atoms that can lead to pore formation (in the side containing the species with the higher product $\bar{V}_{i} M_{i}$ ) by the so-called Frenkel effect $[14,19,20]$ in the bulk as well as on the grain boundary [21,22]. Since copper is the species in which this porosity could appear, it can lead to the loss of bellows airtightness. Furthermore, the development of stresses can lead to crack initiation and propagation in the nickel or copper layers. Finally, grain boundary diffusion can accelerate creep in materials [23].

An applied mechanical load (and the previous self-balancing stresses) can modify the diffusion behaviour through a thermodynamic effect (e.g., effect of pressure) on the diffusion coefficient or through a kinetic effect on the atomic fluxes (e.g., effect of a stress gradient). The effect of pressure on diffusion is known to occur for lattice interdiffusion [24, 25, 26] and is 


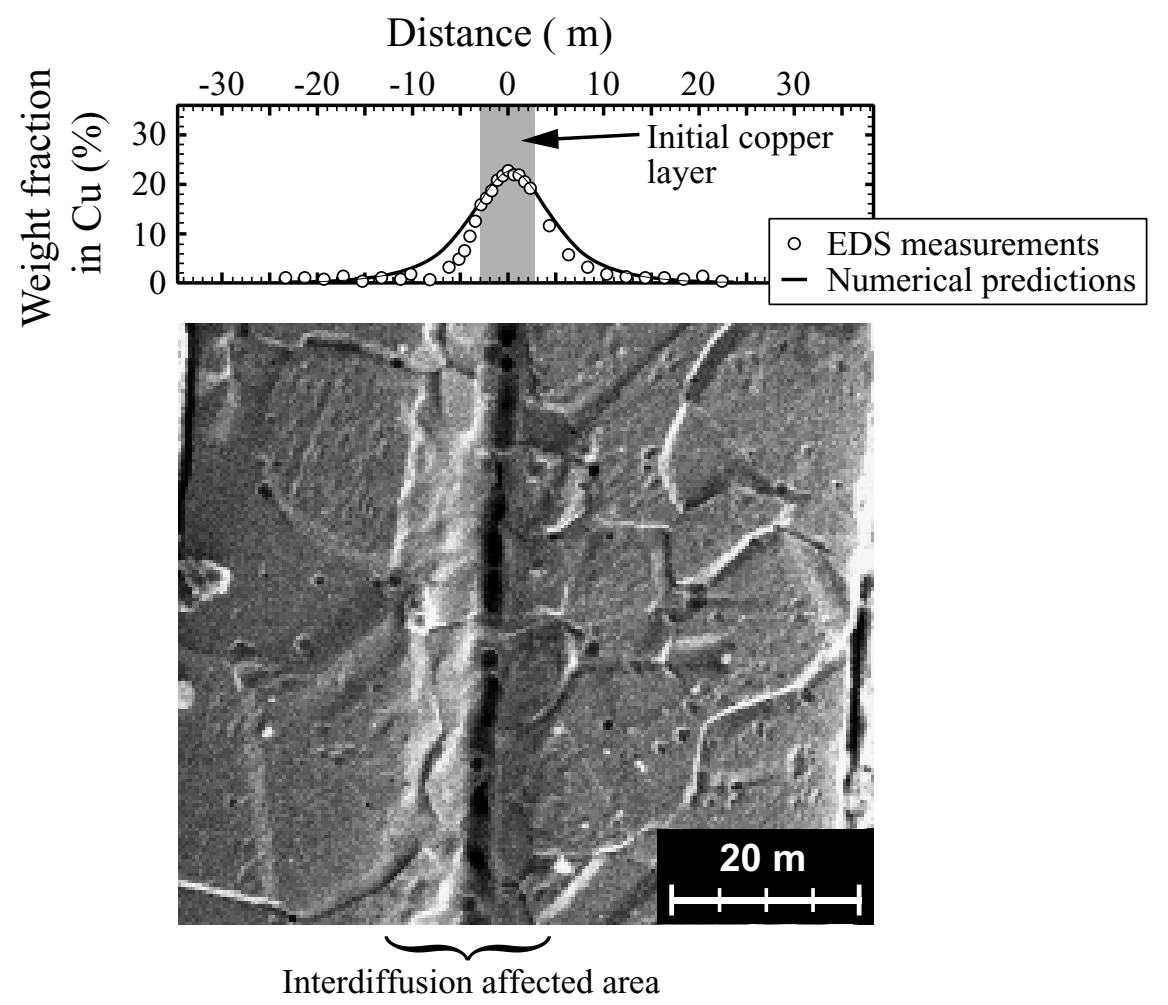

Fig. 4. Measured and predicted weight fraction in copper of a bellows after heat treatment at $780^{\circ} \mathrm{C}$ for $15 \mathrm{~min}$. Note the (strong) grain growth and its interaction with diffusion revealed by chemical etching [2] (SEM micrograph).

related to the diffusion coefficient by

$$
D_{p}=D_{p=0} \exp \left(-\frac{p \Delta V}{R T}\right)
$$

where $p$ is the pressure (i.e., $p=-\operatorname{trace}(\underline{\underline{\sigma}}) / 3$ with $\underline{\underline{\sigma}}$ the stress tensor), $\Delta V$ the activation volume that corresponds, when selfdiffusion is concerned, to the change in volume of the crystal associated with defect formation and atomic jump (i.e., migration). In the case of interdiffusion, the activation volume contains additional terms corresponding to the presence of impurities [27]. Finally, $R$ is the gaz constant and $T$ the absolute temperature. The previous equation only depends on the hydrostatic part of the stress tensor but it is not excluded that other components of the tensor (i.e., shear stresses) can affect diffusion by a similar thermodynamic effect [28]. The effect of pressure on grain boundary diffusion has also been studied [29, 30]. Equation (2) shows that an increasing pressure slows down diffusion if $\Delta V$ is positive (which is generally the case [27]). The other aspect concerns a stress gradient that has been introduced by Larché and Cahn [31, 32, 33] and Stephenson [7]. This affects the flux of species $i$ and can be summarised by the following modification in the Fick's law for a one dimensional binary diffusion case under a pressure gradient only $[10,8]$

$$
J_{i}^{\prime}=-D_{i} \frac{\partial C_{i}}{\partial x}-\frac{D_{i} C_{i} \bar{V}_{A} \bar{V}_{B}}{R T \theta} \frac{\partial p}{\partial x},
$$

where $\theta$ is the Darken's thermodynamic factor. The right hand side of Eq. (3) is a non-Fickian term called Nernst-term that represents a part of the basic phenomena that can modify significantly the diffusion kinetic as mentioned in the previous paragraph for the Kirkendall effect 
(in this case, other phenomena like plastic flow are involved). A more direct effect of the phenomenon described by Eq. (3) has been recognised earlier for diffusion of hydrogen in steel and has been referred to as the Gorsky effect [34, 35]. The Gorsky experiment is based on a steel bar in which a uniform hydrogen concentration is initialy present. Bending this bar leads to an enrichment of hydrogen in the tensile part of the specimen and the opposite effect in the compressive part. An other example is the formation of impurity clouds around edge dislocations, e.g., the Cottrel atmosphere [36]. In this case, the impurities are attracted (or repulsed) by the dislocations via the stress field created by the dislocations. Similar effects are observed for water transport in Agar gel [37, 38] where a modification in the dependence of apparent diffusion coefficients with the concentration is described. Furthermore, in these cases, the diffusion species are mainly interstitial atoms but the previous remarks apply for vacancy diffusion mechanisms. This study has been extended to the case of grain boundary diffusion [29, 39]. Furthermore, the previous equation is expressed for a pressure gradient, its general expression contains any component of the stress gradient tensor since the modification in the flux is due to a gradient in the elastic energy density $\nabla\left(\underline{\underline{\sigma}}: \underline{\underline{\varepsilon}}_{\mathrm{e}}\right) / 2$, where $\underline{\underline{\varepsilon}}_{\mathrm{e}}$ is the elastic strain tensor (see e.g., Eqs. (40) and (48) in Ref. [7]). Moreover, stresses can modify or completely prevent the Frenkel effect of pore formation $[19,12]$. Note that the 'external' stress can arise from a thermal expansion coefficient mismatch $\left(\right.$ e.g., $\left.\alpha_{\mathrm{Cu}}>\alpha_{\mathrm{Ni}}\right)$. It is important to note that, according to the Curie's principle, fluxes originate in gradients of the intensive thermodynamic variables [8, 28] (e.g., a uniform stress cannot give rise to a diffusion flux but it can slow down or accelerate the process) and similar additional Nernst-term in the Fick's law can be used to model the effect of a temperature gradient on diffusion [28]. In this case, Eq. (3) can be rewritten as

$$
J_{i}^{\prime}=-D_{i} \frac{\partial C_{i}}{\partial x}-\frac{D_{i} C_{i} Q^{*}}{R T^{2}} \frac{\partial T}{\partial x}
$$

where $Q^{*}$ is a thermodynamic factor. But the thermal conditions during experiments or for the real component are generally such that the characteristic time for temperature homogenisation is much smaller than diffusion characteristic time. The effect of a temperature gradient is therefore neglected here.

In the present case, since the material grain size is bound to evolve, grain growth or recrystallisation may occur. This will be particularly true during an annealing treatment for the study of diffusion (see Figs. 1 and 4). The effect of a moving grain boundary on the diffusion analysis has been treated for diffusion on a single grain boundary [40,41] and in a polycrystal containing a fraction of moving grain boundaries [42]. It can lead one to underestimate the grain boundary diffusion coefficient since the penetration depth in a moving grain boundary is smaller by a factor $(V t / \sqrt{D t})^{1 / 2}$, where $V$ is the (constant) grain boundary velocity, $t$ the diffusion time and $D$ the average lattice diffusion. In this case, new diffusion regimes can appear depending on the velocity, $V$, the grain boundary diffusion coefficient $D_{\mathrm{b}}$, the lattice one $D$ and the grain size $d[40,43]$. Lastly, the dislocation density influences the apparent lattice diffusion since dislocations (and subgrain boundaries) represent diffusion short-circuit paths and, if their density is significant, a new grain boundary diffusion regime, say D, appears [44]. Conversely, diffusion can modify or influence the grain size and distribution by the diffusion-induced grain boundary migration (DIGM) [24, 42, 22] and diffusion-induced recrystallisation (DIR) [45]. It is interesting to notice in Fig. 4 that grain growth in the interdiffusion affected area seems slower than in pure nickel.

Finally, strain and plasticity can affect recrystallisation such as what can be described (and used) in metal rolling for the grain size control of metallic sheets [46]. Conversely, the grain size and distribution (i.e., texture) play an important role in the plastic behaviour of metals. For example, grain growth or recrystallisation generally lead to a decrease in dislocation density, 
thus, they modify the global texture and the yield stress $\sigma_{y}$ since it can be related to the grain size $d$ by, say, the empirical Hall-Petch relationship [47]

$$
\sigma_{y}=\sigma_{i}+\frac{k_{y}}{\sqrt{d}}
$$

that applies for nickel used in the present case [2] where $\sigma_{i}$ is an 'internal' stress which is related to the shear stress threshold for dislocation glide (approximately equal to 40MPa) and $k_{y} \sim 0.48 \mathrm{MPa} \sqrt{\mathrm{m}}$. For very fine-grained materials, the yield stress can be governed by other mechanisms than dislocations glide and lead to a reverse Hall-Petch effect [48]. This 'mesoscopic' yield stress associated with the material 'texture', the porosity and the concentration curve are needed to determine the macroscopic yield stress of a cross section of the multilayered material. Porosity reduces the macroscopic yield stress [49]. The diffusion of copper could lead to a significant modification in the macroscopic plastic behaviour since its diffusion on the grain boundaries could lead to a brittle (intergranular) fracture mechanism instead of ductile failure as it has been observed experimentally [50].

This overview of the main couplings of interest in the present study of ageing shows the complexity of the problem and it is not possible to treat (numerically or experimentally) all the effects simultaneously and only the relevant effects must be considered. However, it is important to keep all of them in mind when interpreting experimental results. The next section focuses on the determination of diffusion parameters for the electroplated multilayered material that will allow for the evaluation of the change of the elastic moduli with time.

\section{Determination of diffusion coefficients}

Bellows are usually utilised at an average temperature close to room temperature. For this range of temperature, grain boundary diffusion is predominant over volume diffusion as it can be seen in Fig. 5. However, the microstructure is small (Fig. 1b) compared to spatial resolution of concentration measurements (electron microprobe is used for measuring diffusion curves, i.e., the characteristic length varies between many hundredths of one micrometer and one micrometer) so that the diffusion curves seem homogeneous in the direction parallel to the interface. The investigations are, for the moment, limited to the determination of global diffusion coefficients including grain boundary diffusion, (weak) lattice diffusion and grain boundary motion due to grain growth (see Fig. 4).

Increasing the temperature enables one to activate the diffusion process and higher rates of diffusion are therefore obtained in reasonable time durations. An Arrhenius plot of many results on diffusion for the $\mathrm{Ni} / \mathrm{Cu}$ couple and different configurations (e.g., lattice diffusion, grain boundary diffusion, coarse grained or (ultra)fine-grained materials) is reported in Fig. 5. This figure summarises the different regimes of diffusion for the material of interest. Grain boundary diffusion is the predominant mode in the temperature range that is relevant to the present study. Moreover, it is interesting to see that results on lattice diffusion are all consistent with each other whereas a strong scatter exists for the grain boundary diffusion parameters. This can arise from the large possibilities (and often unknown average values) and sensitivity for the grain boundary misorientation angle and the difficulty for extracting the basic diffusion coefficients in polycrystal specimen from the concentration measurements especially at moderate temperatures where grain boundary motion can occur. This is especially true for fine-grained materials [43] even if a specific treatment exists for a unique moving grain boundary [40] and in a polycrystal with a fraction of moving grain boundaries [42] but they are limited, up to now, to the case of non-interacting grain boundaries. This is not the case in the present study for an annealing treatment (just compare the microstructure in Fig. 1 to that in Fig. 4). 


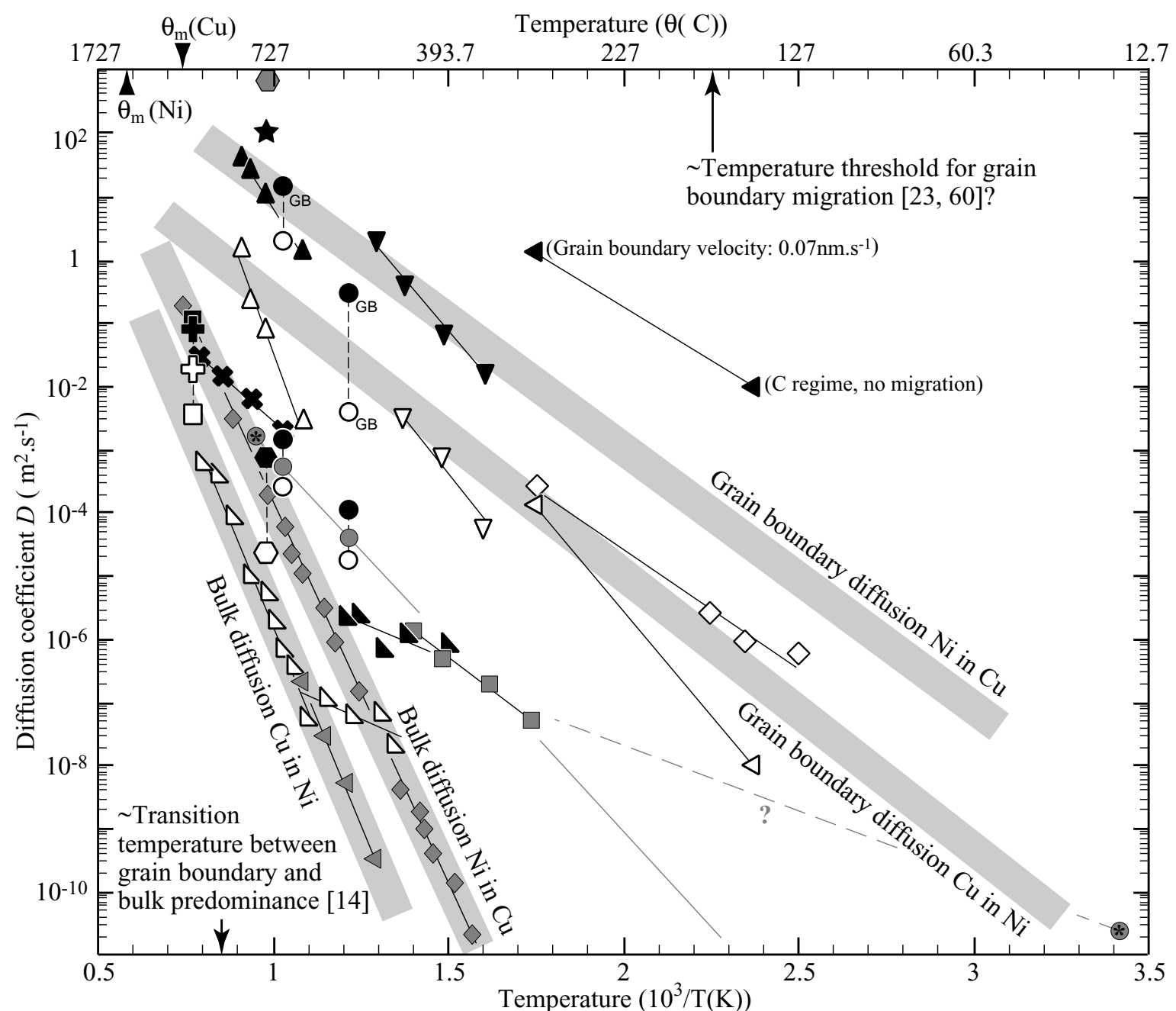

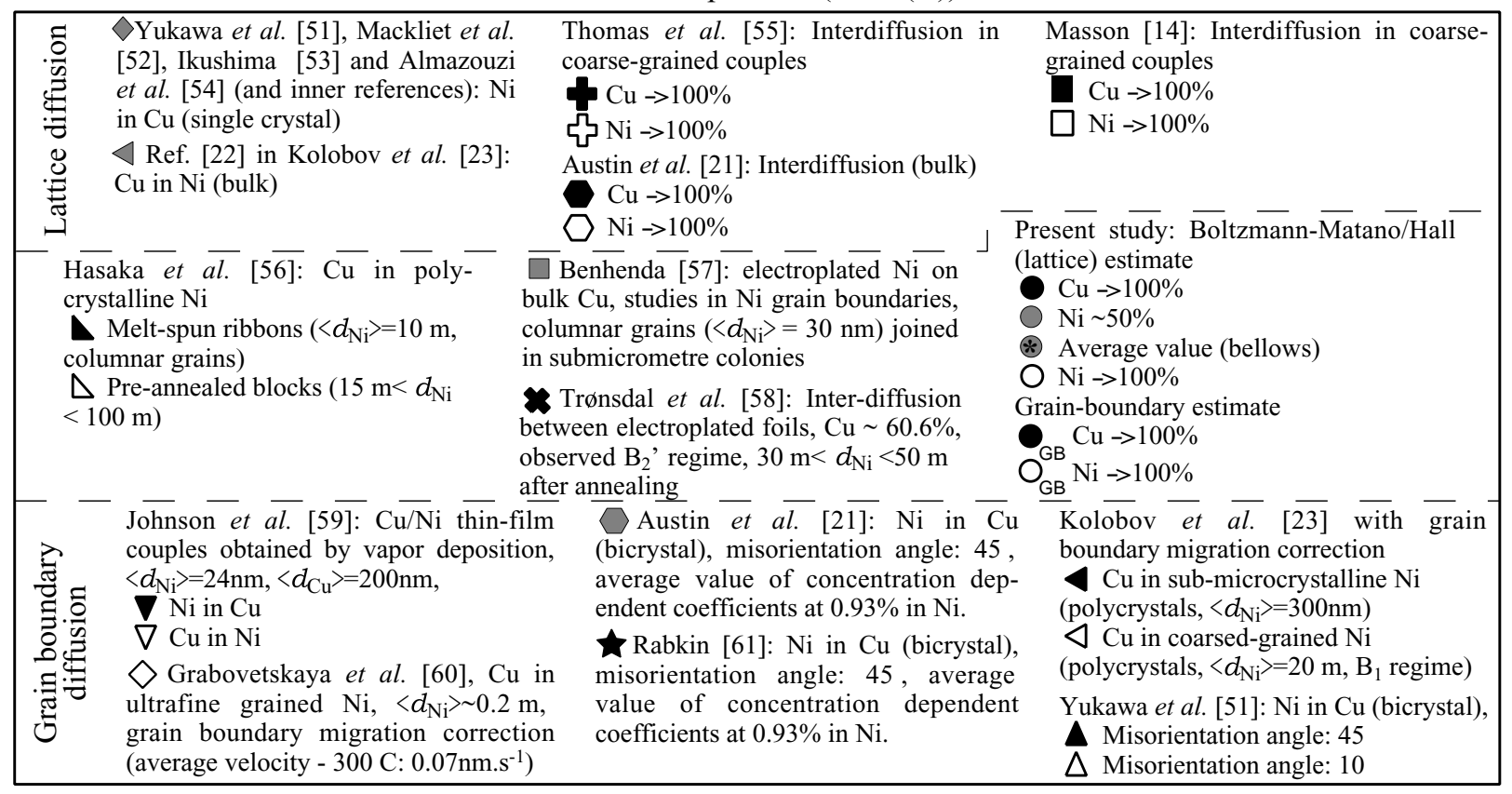

Fig. 5. Arrhenius plot for the change of global diffusion coefficients with temperature for $\mathrm{Ni} / \mathrm{Cu}$ couples. All compositions are given in weight fraction, $\theta_{\mathrm{m}}$ stands for the melting temperature. Grain boundary diffusion coefficients are plotted by assuming that the grain boundary width, $\delta$, is independent on the temperature and is equal to $0.5 \mathrm{~nm}[42]$ and that the segregation factor is close to one at every temperature [27]. 
The evaluation of diffusion coefficients requires low scales of observation. Therefore, practical studies are performed by an EDS (i.e., Energy Dispersive Spectroscopy) method in an SEM. It enables one to identify and quantify the elemental chemical composition within a depth of about one micrometer. A mass concentration resolution of about one percent can be obtained in suitable conditions, i.e., measurement artefacts, or effects, must be considered. Softwares used to analyse the results of an EDS microprobe usually correct standard measurement effects but they assume a homogeneous concentration in the analysed area. However, in the present case, diffusion occurs only over a few micrometers (see Fig. 4) and the concentration is no longer constant in the analysed area. One measures an average of the real concentration and that can lead to overestimate the actual diffusion coefficient [62]. It is called average effect and is caused by the X-ray emission volume whose characteristic length, $l_{\mathrm{X}}$, can be of the same order of magnitude as the penetration length of diffusion, $2 \sqrt{D t}$, where $D$ is the (true) diffusion coefficient. A simplified quantitative study of this phenomenon in the case of close atomic number elements (such as nickel and copper), if no dependence of the diffusion coefficient with the composition is assumed, has shown that the apparent diffusion coefficient $D^{*}$ measured by an EDS probe follows the simple law

$$
D^{*}=D+\frac{l_{\mathrm{x}}^{2}}{2 t}
$$

that shows the need of taking this effect into account in the determination of the diffusion coefficient [62]. A more detailed study of the specific physical effects occurring in this kind of measurements has been developped in Ref. [63] and a complete deconvolution procedure of concentration measurements with concentration-dependent diffusion coefficients is proposed in Ref. [64].

Usually, the Boltzmann-Matano method [24] is applied to evaluate the diffusion coefficient, which is dependent on the chemical composition, from the deconvoluted concentration profiles for intermediate concentrations. An additional method is necessary for the low and high concentration parts of diffusion curves since the previous one is less accurate in these extreme domains. The Hall method is well-adapted to this kind of study [24]. The diffusion curves have been obtained on specific specimen (i.e., 'semi-infinite' bilayered diffusion couples for which the layer thicknesses are sufficient to prevent the diffusing species to reach a free surface) and not on bellows. But three important remarks (or improvements) have to be made:

- this method applies for lattice and only for grain boundary diffusion in the 'A' regime [42] when dealing with the average diffusion curve in the direction perpendicular to the diffusion one. In this kind of grain boundary diffusion, the global interdiffusion coefficient follows a mixing rule of the lattice and grain boundary diffusion coefficients via the volume fraction of grain boundaries (i.e., the so-called Hart equation [42] whose validity has been recently studied for fine-grained materials [65]). The grain boundary diffusion regime(s) has to be clearly specified in the present study and if other regimes of grain boundary diffusion happen, a specific treatment may be developed to treat the diffusion curve [27]. It can be based on the determination of interdiffusion coefficients on grain boundary $[21,61]$ that is, for the moment, 'limited' to the case of constant lattice diffusion and for dilute solid solutions. Grain boundary diffusion has been confirmed by plotting average diffusion curves, on many positions along the initial interface, in the $\left(x^{6 / 5}, \ln (C)\right)$ coordinates [42] where well-defined (considering the accuracy of EDS measurements) straight lines appear for the tails in each diffusion profile (i.e., $\mathrm{Ni}$ and $\mathrm{Cu}$ ). The Le Claire analysis $[42,27]$ has been applied on these parts of the curves and the results are reported in Fig. 5. They only give a rough estimate of the grain boundary diffusion coefficient since, in the present case, (fine) polycrystals are concerned (and not a network of parallel grain boundaries) 


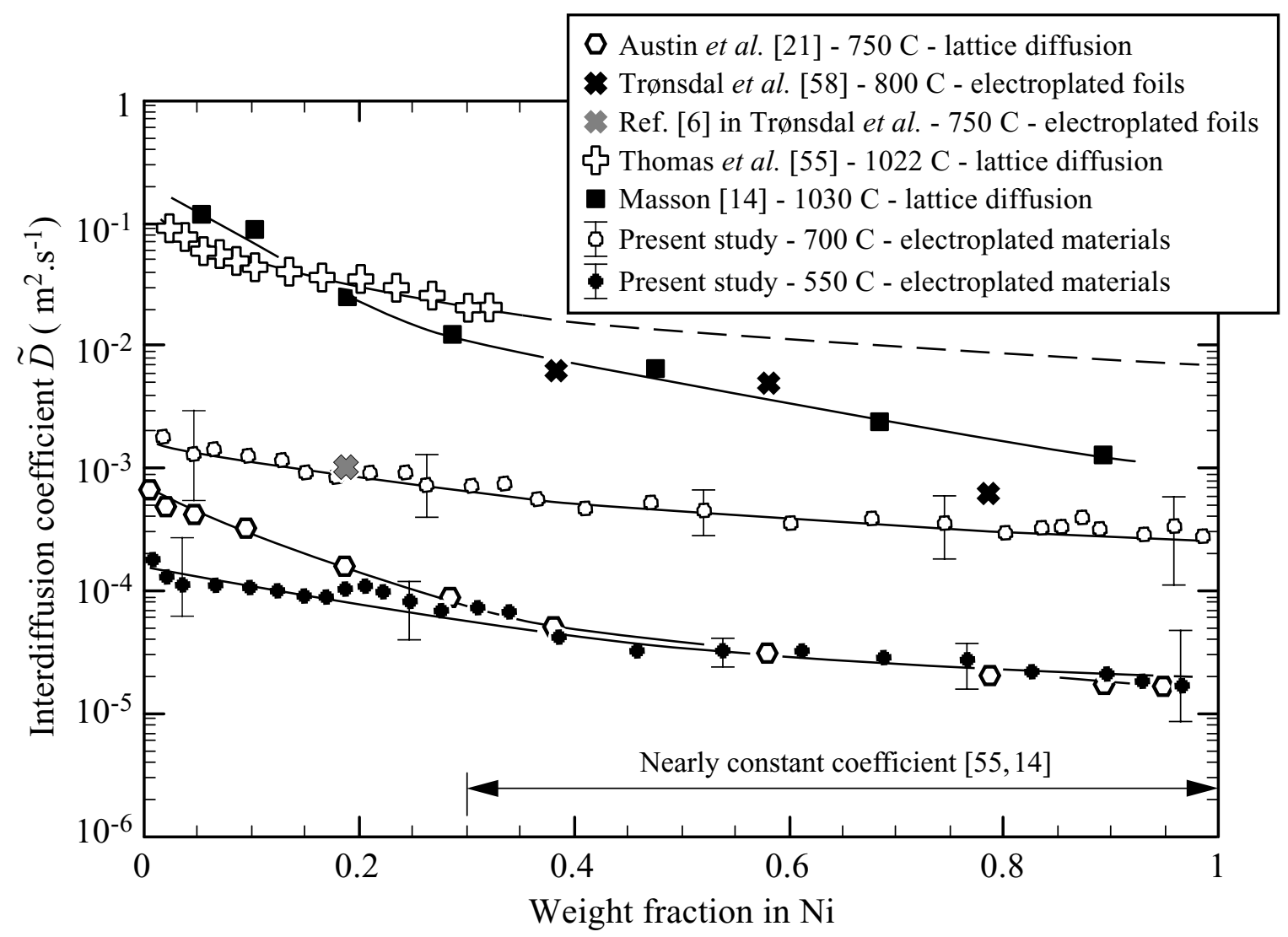

Fig. 6. Change of the global interdiffusion coefficient with the weight fraction in nickel for $\mathrm{Ni} / \mathrm{Cu}$ couple. Scatter in the coefficient (depicted by the error bars) is due to the precision of the EDS measurements and (weak) variations of the diffusion curves in the direction parallel to the initial interface. The straight lines depict the main tendency of the different results and the values obtained in the present case for average diffusion curves for many measurements at different positions along the initial interface.

even if the Le Claire's analysis can be applied to polycrystals when the average grain boundary misorientation angle is known $[42,27]$ ). Furthermore, the initial and boundary conditions in concentration for the grain boundary diffusion analysis is not well-defined here even if it seems to be close to a constant concentration. In spite of these restrictions, the extracted values are surprisingly well correlated with other grain boundary results (since the next item has to be considered too),

- strong grain growth occurs for fine-grained materials and this effect must be accounted for since the apparent diffusion coefficient is less than the real one due to grain boundary migration (see the previous section). This has been performed in Refs. [23, 60] for this kind of material but it appears that it exists no specific techniques when the grain boundary interacts during the grain growth process,

- the Kirkendall effect implies that a local volume change occurs and the Boltzmann-Matano method could lead to wrong interdiffusion coefficients. This can be assessed by using the Sauer-Freiser method [66].

As a first approximation, with the Boltzmann-Matano/Hall method, the change of the interdiffusion coefficient with the concentration has been obtained at $700^{\circ} \mathrm{C}$ and $550^{\circ} \mathrm{C}$ on specific samples. The results are shown in Fig. 6 together with other results for lattice diffusion and for 
fine-grained (electroplated) material interdiffusion with a similar treatment of the data. The shape of the curves is consistent with classical results, i.e., the dependence of the diffusion coefficient with the elemental composition increases with the copper concentration. This is generally the case, i.e., a diffusion coefficient increases with the concentration of the lowest melting temperature compound [14, 67]. But some results on grain boundary concentration-dependent diffusion coefficients should be mentionned where the opposite dependence is observed [61]. However, the present diffusion coefficients are greater than those obtained for lattice interdiffusion (and less than those for grain boundary interdiffusion). This follows the previous remarks on the possible improvements in the determination of the diffusion coefficient from concentration profiles. In fact, the prevalent mechanism is grain boundary diffusion and the effect of a moving grain boundary has to be included.

Since the (inter)diffusion coefficients have been identified at two testing temperatures, the coefficient of thermal activation of the Arrhenius law is known, with an average value of about $110 \mathrm{~kJ} . \mathrm{mol}^{-1}$ for temperatures ranging from $550^{\circ} \mathrm{C}$ to $700^{\circ} \mathrm{C}$. The results are shown in Fig. 5 together with average estimates of diffusion coefficients of bellows obtained by fitting the solution of the Fick's law for a constant lattice diffusion coefficient and bilayered material configurations. It is important to note that the results obtained by the Boltzmann-Matano/Hall method seem to be consistent with other studies on electroplated or fine-grained copper/nickel materials $[58,57]$ by using similar approaches (i.e., no correction for grain boundary motion and determination of an apparent 'lattice' diffusion coefficient with the Boltzmann-Matano method or equivalent) even if the coefficient of thermal activation seems to be lower in other results than in the present study.

Numerical diffusion simulations for any time duration, geometry and temperature (in the same range as in the tests) can be performed. This has been carried out by using the heat transfer module in the finite element code CAST3M and the equivalence between the equations of heat transfer and atomic diffusion. Validations of the previous measurements have been carried out on bellows with a complex temperature cycle. Very good agreement is observed between the prediction and the deconvoluted measurement (Fig. 4) even if this simulation does not take explicitly into account grain growth, grain boundary diffusion and volume change. It is simply based on the numerical solution of the Fick's and conservation laws for 'lattice' interdiffusion. However, as expected, these coefficients, especially the dependence of the linear extrapolation of the thermal activation coefficient to lower temperatures, are not able to simulate the observed diffusion on bellows aged at room temperature during 20 years (Fig. 5). This point seems to lie in the grain boundary diffusion domain. This is not completely surprising since, at this temperature, grain growth is very low (as diffusion) and the corresponding correction is small. The 'quality' of this 'lattice mechanism-based' result for a grain boundary diffusion coefficient can be partially explained by the diffusion regime that may occur here (close to a ' $\mathrm{C}$ ' one [42] since the penetration depth is of the same order of magnitude as the grain size) and the fact that the boundary condition in concentration is close to a constant source. The grain boundary diffusion curve is then similar to a lattice diffusion one and it is described by an error function [42]. However, the overall diffusion parameters determined previously, even if they contain a lot of different phenomena, can be used to simulate approximate but realistic (Fig. 4) concentration curves. This allows us to determine a first estimate of the change of the elastic coefficients with time and to draw conclusions on long-term reliability of bellows with respect to their stiffness change induced by diffusion. 


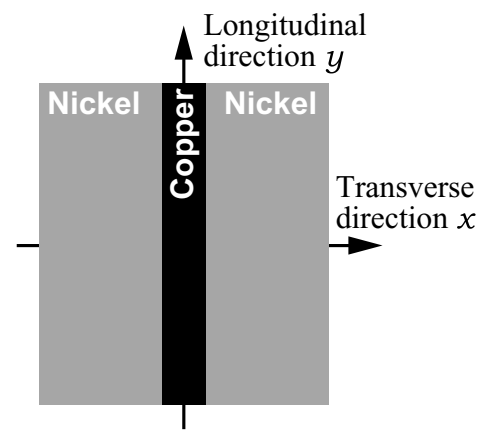

Initial bilayered material
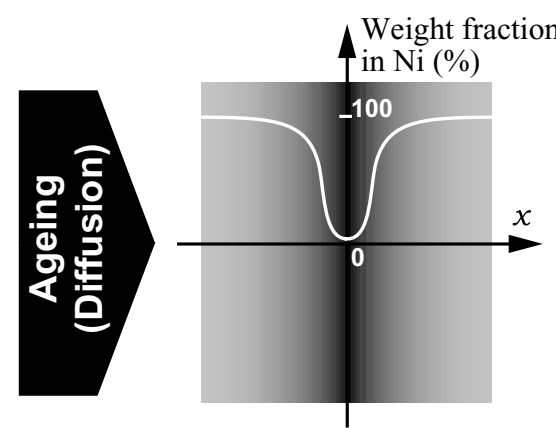

Multilayered material at time $t$
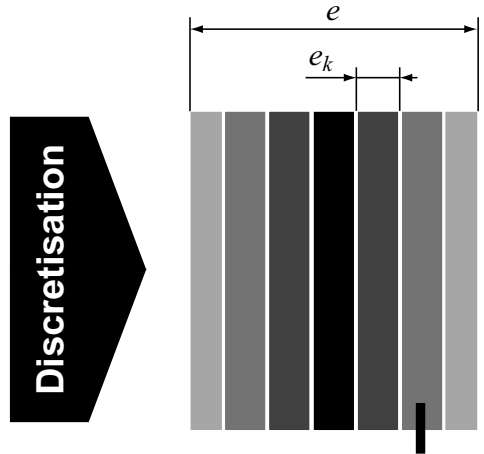

Multilayered material with piecewise constant chemical concentration

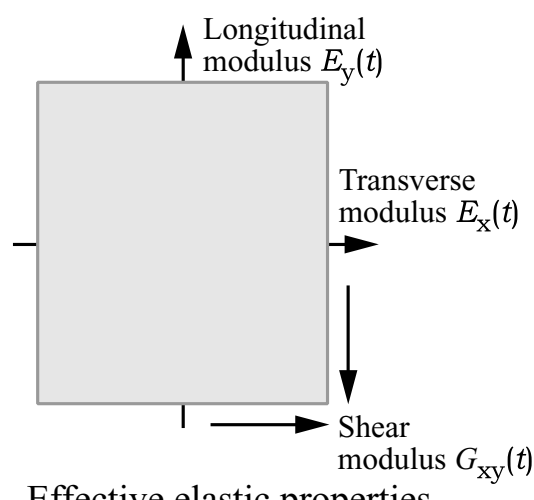

Effective elastic properties
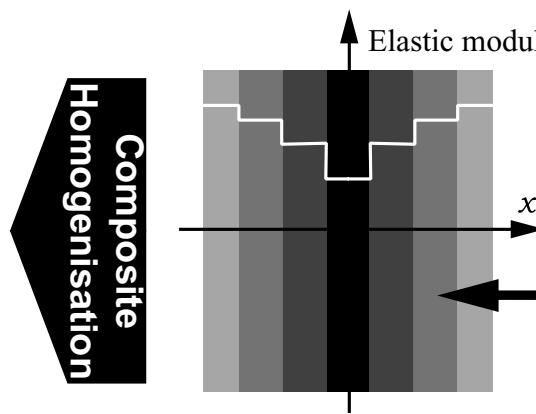

Laminate composite with isotropic layers

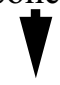

Diffusing species on grain boundaries

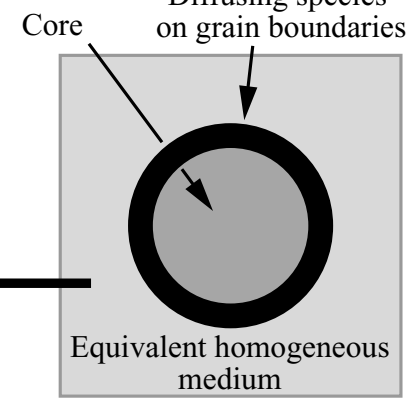

Three-phase self-consistent homogenisation pattern

Fig. 7. Homogenisation steps to predict the overall (i.e., macroscopic) elastic properties during chemical diffusion of $\mathrm{Ni} / \mathrm{Cu}$ bellows.

\section{Changes of elastic moduli induced by diffusion}

The change of the effective elastic properties (i.e., transverse $E_{\mathrm{x}}$ and longitudinal $E_{\mathrm{y}}$ Young's modulus, and in-plane shear modulus $G_{\mathrm{xy}}$ where longitudinal means parallel to the interfaces between nickel and copper, see Fig. 7) of the bilayered material with the diffusion process is evaluated. Since the Poisson's ratios, $\nu$, of the two materials are very close, they are assumed to be equal. The determination of the effective coefficients, when the chemical composition is known, is illustrated in Fig. 7. The diffusion profiles are discretised into $N$ layers of thickness $e_{k}$ to obtain a multilayered material in which each layer is assumed to have a constant chemical composition and to be isotropic. The effective elastic moduli of each layer is obtained by using a homogenisation scheme consistent with the assumed principal diffusion mode: grain boundary diffusion in a fine-grained material (see microradiograms in Ref. [58]), i.e., between the $\mathrm{C}^{\prime}$ and $\mathrm{B}_{2}^{\prime}$ regimes defined in Ref. [43]. Therefore, in the initial nickel layer, nickel grains are surrounded by copper and the opposite situation is found in the copper layer (Fig. 8a). The generalised three-phase self-consistent scheme $[68,69]$ is the most suitable one. It consists in determining the effective equivalent modulus of a spherical isotropic inclusion surrounded by a second isotropic phase, this whole pattern being embedded in an infinite medium whose elastic moduli is the expected mesoscopic one, i.e., the equivalent homogeneous medium (see Fig. 7). The effective isotropic elastic modulus for the $k^{\text {th }}$ layer is given by the following explicit formula for the bulk 


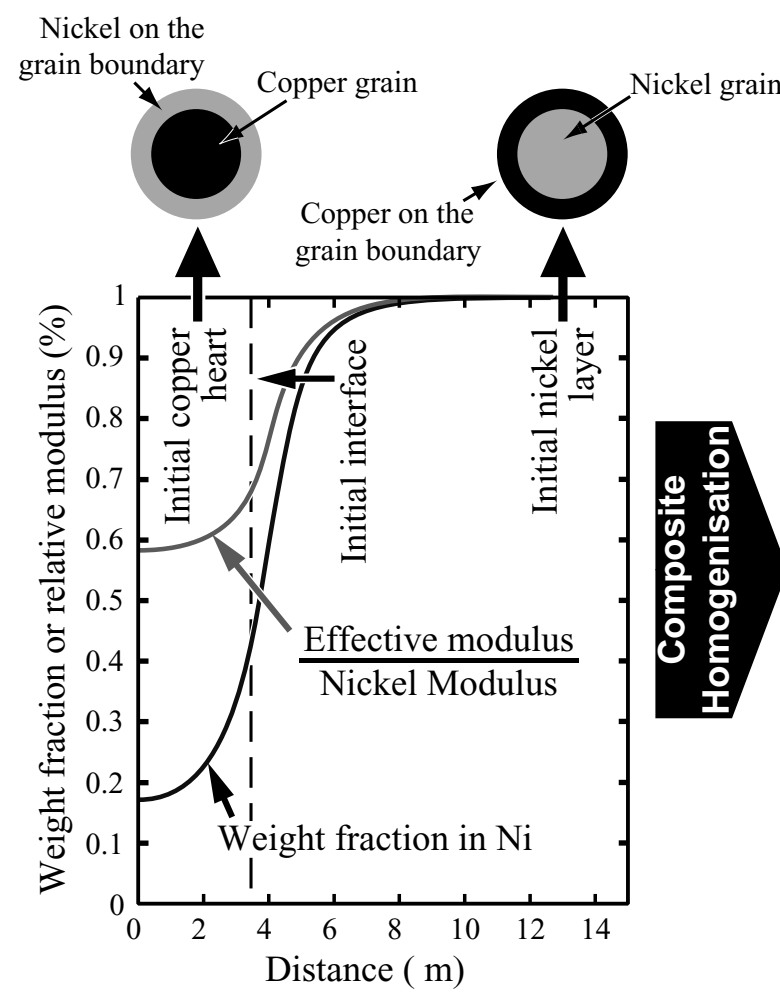

(a)

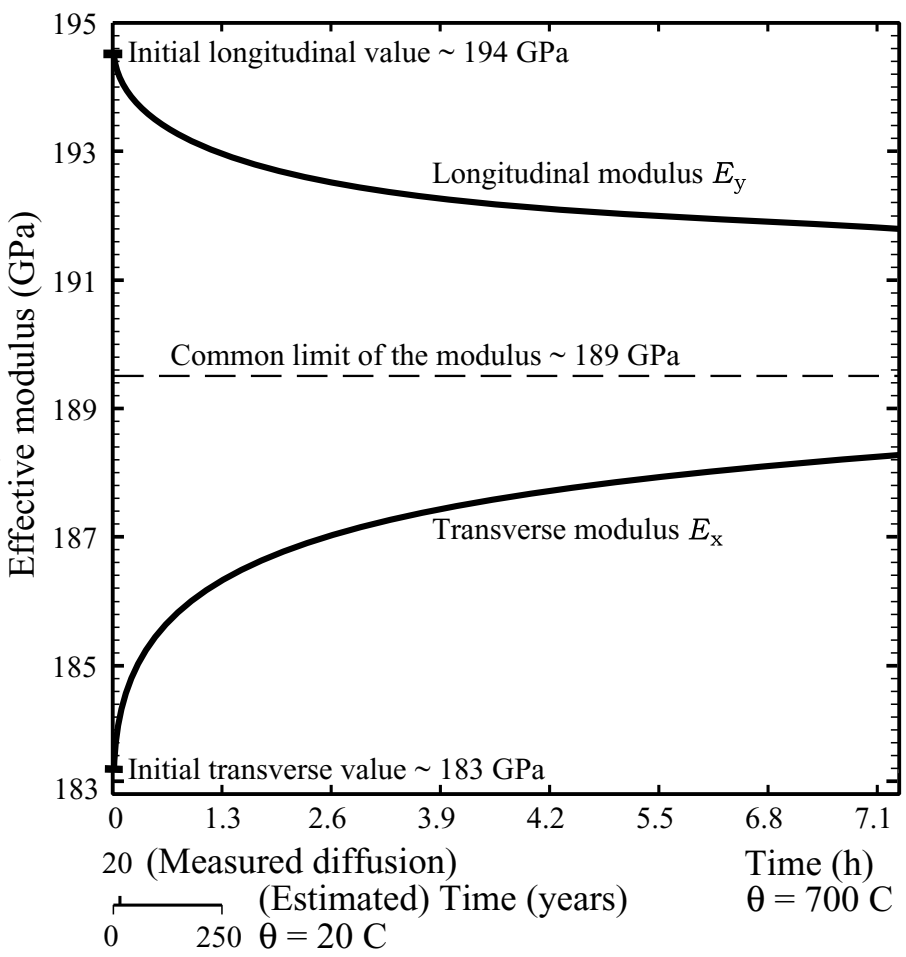

(b)

Fig. 8. First homogenisation step (Self-consistent scheme of a piecewise constant chemical concentration) for one half of the bilayered material, with a thicker copper layer than in Fig. 1b, for 37min of diffusion at $700^{\circ} \mathrm{C}$. Effective elastic modulus vs. time for diffusion at $700^{\circ} \mathrm{C}$ and an estimate of the equivalent time for $20^{\circ} \mathrm{C}$.

modulus $K_{k}$

$$
K_{k}=K_{\mathrm{gb}}+\frac{C_{\mathrm{g}_{k}}^{\prime}\left(K_{\mathrm{g}}-K_{\mathrm{gb}}\right)}{1+\left(1-C_{\mathrm{g}_{k}}^{\prime}\right)\left(K_{\mathrm{g}}-K_{\mathrm{gb}}\right) /\left(K_{\mathrm{gb}}+4 G_{\mathrm{gb}} / 3\right)},
$$

where $C^{\prime}$ stands for the volume fraction determined by the weight fraction $C$ and the densities of the different material, $\cdot g$ is the quantity $\cdot$ of the material of the considered grain (inner core of the homogenisation pattern, Fig. 7 ) and $\cdot_{\mathrm{gb}}$ for the material on the grain boundary (concentric shell of the homogenisation pattern, Fig. 7). The shear modulus $G_{k}$ is the positive second root of a second order equation

$$
\alpha\left(\frac{G_{k}}{G_{\mathrm{gb}}}\right)^{2}+\beta\left(\frac{G_{k}}{G_{\mathrm{gb}}}\right)+\gamma=0,
$$

where $\alpha, \beta$ and $\gamma$ depend on $G_{\mathrm{g}}, G_{\mathrm{gb}}, C_{\mathrm{g}_{k}}^{\prime}$ and Poisson's ratio $\nu$ [69]. The Young's modulus and the Poisson's ratio are then deduced

$$
\begin{aligned}
E_{k} & =\frac{9 K_{k} G_{k}}{3 K_{k}+G_{k}}, \\
\nu_{k} & =\frac{3 K_{k}-2 G_{k}}{6 K_{k}+2 G_{k}} .
\end{aligned}
$$

In the present case, the Poisson's ratios are assumed to be identical for the two materials but this does not yield $\nu_{k}=\nu$. Equations (7) and (8) lead to two possible results for the effective 
elastic modulus and Poisson's ratio depending on which material the inner core is made of. The two results are needed (see Fig. 8a) since it is assumed that copper diffuses on the grain boundaries of nickel grains in the layers containing nickel initially and conversely in the initial copper layer. When this first step is completed, a composite-like material is obtained with $N$ isotropic elastic layers of effective Young's modulus $E_{k}$ and Poisson's ratio $\nu_{k}$ (Fig. 8a). A homogenisation scheme applied to isotropic laminated composite materials [70] is used to evaluate the overall transversely isotropic elastic properties (Fig. 7)

$$
\begin{aligned}
E_{\mathrm{x}} & =\left(\sum_{k} \frac{e_{k}}{e} \frac{1}{E_{k}}\right)^{-1}, \\
E_{\mathrm{y}} & =\sum_{k} \frac{e_{k}}{e} E_{k}, \\
G_{\mathrm{xy}} & =\left(\sum_{k} \frac{e_{k}}{e} \frac{2\left(1+\nu_{k}\right)}{E_{k}}\right)^{-1} .
\end{aligned}
$$

The final result is shown in Fig. $8 \mathrm{~b}$ for $E_{\mathrm{y}}$ and $E_{\mathrm{x}}$. The magnitude of variation of the moduli depends on the relative thickness of the copper and nickel layers. The maximum magnitude of variation is obtained in a relatively short time duration, i.e., an ageing mode induced by diffusion could be significant even for low time durations or temperatures. For example, a rough approximation based on an equivalence on the average rate of diffusion for a 20 year aged material gives an idea of the corresponding time duration at room temperature. Since the stiffness of bellows is proportional to the longitudinal modulus (for relatively low deflections), diffusion could have a non-negligible effect on the overall behaviour of the component if the copper layer is too thick. The same treatment can be applied to the thermal conductivity and coefficient of thermal expansion with the same self-consistent schemes [71, 72]. It is important to note that the previous results are all based on the assumption that each material grain can be modelled by a homogeneous spherical inclusion surrounded by a homogeneous shell. This assumption is only valid for small grain sizes compared to the layer thickness. This will no longer be the case for materials with strong recrystallisation rates. Moreover, the real grain and grain boundary morphologies can play an important role in the effective properties [73, 74].

\section{Conclusions}

A general view of the main couplings concerned in the study of ageing of electroplated bellows has been introduced and a first determination of global diffusion coefficients has been performed. Simulations of approximate diffusion curves containing grain growth, grain boundary and lattice diffusion at any time are possible with the determined coefficients. Effective elastic moduli are obtained at each time with a self-consistent scheme and allow us to conclude on the stiffness changes of bellows induced by diffusion. However, all the effects occurring during annealing treatments have to be studied separately if a comprehensive treatment of them on the change in the elasto-plastic properties of the material with time is expected. This is especially true when extrapolations to low temperatures are needed. Moreover, diffusion could have an effect on the airtightness of bellows as it degrades the copper barrier and, if the Frenkel effect is confirmed, porosity could nucleate in copper and lead to crack initiation under monotonic or cyclic mechanical loadings. A competitive phenomenon occurs in the nickel layers where the Kirkendall effect tends to put them in compression. The initial porosity due to the electroplating process for nickel could decrease and then ensure the airtightness of bellows. Finally, this study provides the basis of the elementary mechanisms that could occur and lead to bellows failure during mechanical and thermal fatigue. 
Acknowledgements. The authors wish to acknowledge useful discussions with Mr. J. Duval from AER company and Dr. N. Schmitt. They also wish to thank Dr D.J. Fisher for inviting them to write this paper.

\section{References}

[1] Arnould, O., Duval, J. and Hild, F., "On the Identification of the Diffusion Ageing Mode of $\mathrm{Ni} / \mathrm{Cu}$ Assemblies", in: Limoge, Y. and Bocquet, J.L. Eds., International Conference on Diffusion in Materials - DIMAT 2000, Paris, France, Defect and Diffusion Forum, Vol. 194-199, pp. 14451450, Scitec Publications, Switzerland, 2001.

[2] Banovic, S.W., Barmak, K. and Marder, A.R., "Microstructural characterization and hardness of electrodeposited nickel coatings from a sulphamate bath", Journal of Materials Science, Vol. 33, pp. 639-645, 1998.

[3] Marquis, D., "Phénoménologie et Thermodynamique : couplage entre thermoélasticité, plasticité, vieillissement et endommagement", Thèse d'État, University of Paris VI, 1989 (in French).

[4] Chevalier, L., Calloch, S., Hild, F. and Marco, Y., "Digital image correlation used to analyze the multiaxial behavior of rubber-like materials", European Journal of Mechanics - A/Solids, Vol. 20(2), pp. 169-187, 2001.

[5] Hild, F., Périé, N. and Coret, M., "Mesure de champs de déplacements 2D par intercorrélations d'images: CORRELI ${ }^{2 D} "$, Internal report 230, LMT-Cachan, 1999 (in French).

[6] Kaye, G.W.C. and Laby, T.H., Tables of physical and chemical constants, $16^{\text {th }}$ edition, Essex, England, 1995.

[7] Stephenson, G.B., "Deformation during interdiffusion", Acta Metallurgica, Vol. 36(10), pp. 2663$2683,1988$.

[8] Beke, D.L., "Why Diffusion and Stresses?", in: Beke, D.L. and Szabó, I.A. Eds., Proceedings of the $1^{\text {st }}$ International Workshop on Diffusion and Stresses, Balatonfüred, Hungary, Defect and Diffusion Forum, Vol. 129-130, pp. 9-30, Scitec Publications, Switzerland, 1996.

[9] Szabó, S., Opposits, G. and Beke, D.L., "Diffusion and Stresses in Multiphase Solids", in: Limoge, Y. and Bocquet, J.L. Eds., International Conference on Diffusion in Materials - DIMAT 2000, Paris, France, Defect and Diffusion Forum, Vol. 194-199, pp. 1431-1436, Scitec Publications, Switzerland, 2001.

[10] Daruka, I., Szabó, S., Beke, D.L., Cserháti, C.S., Kodentsov, A. and Van Loo, F.J.J., "Diffusioninduced bending of thin sheet couples: theory and experiments in Ti-Zr system", Acta Materialia, Vol. 44(12), pp. 4981-4993, 1996.

[11] Szabó, S., Daruka, I. and Beke, D.L., "Non-Local Effect of Stress", in: Beke, D.L. and Szabó, I.A. Eds., Proceedings of the $1^{\text {st }}$ International Workshop on Diffusion and Stresses, Balatonfüred, Hungary, Defect and Diffusion Forum, Vol. 129-130, pp. 127-134, Scitec Publications, Switzerland, 1996.

[12] Opposits, G., Szabó, S., Beke, D.L., Guba, Z. and Szabó, I.A., "Diffusion-induced bending of thin sheet diffusion couples", Scripta Materialia, Vol. 39(7), pp. 977-983, 1998.

[13] Smigelskas, A.D. and Kirkendall, E.O., "Zinc diffusion in alpha brass", Transaction of the AIME, Vol. 171, pp. 130-142, 1947. 
[14] Masson, B., "Etude comparée de l'influence de l'effet Kirkendall sur la porosité des couples de diffusion $\mathrm{Cu}-\mathrm{Ni}$ en métaux massifs et sur celles des mélanges de poudres $\mathrm{Cu}-\mathrm{Ni}$ au cours de leur frittage", Ph.D. Thesis, University of Paris Sud - Orsay, 1966 (in French).

[15] Schlipf, J., "On the plastic deformation associated with the Kirkendall effect", Acta Metallurgica, Vol. 21, pp. 435-440, 1973.

[16] Van Dal, M.J.H., Pleumeekers, M.C.L.P., Kodentsov, A.A. and van Loo, F.J.J., "Intrinsic diffusion and Kirkendall effect in Ni-Pd and Fe-Pd solid solutions", Acta Materialia, Vol. 48(2), pp. 385$396,2000$.

[17] Larché, F.C. and Cahn, J.W., "The effect of self-stress on diffusion in solids", Acta Metallurgica, Vol. 30, pp. 1835-1845, 1982.

[18] Greer, A.L., "Stress Effects on the Interdiffusion in Amorphous Multilayers", in: Beke, D.L. and Szabó, I.A. Eds., Proceedings of the $1^{\text {st }}$ International Workshop on Diffusion and Stresses, Balatonfüred, Hungary, Defect and Diffusion Forum, Vol. 129-130, pp. 163-180, Scitec Publications, Switzerland, 1996.

[19] Paritskaya, L.N. and Bogdanov, V.V., "Stress sensitive effect in diffusion zone", in: Beke, D.L. and Szabó, I.A. Eds., Proceedings of the $1^{\text {st }}$ International Workshop on Diffusion and Stresses, Balatonfüred, Hungary, Defect and Diffusion Forum, Vol. 129-130, pp. 79-94, Scitec Publications, Switzerland, 1996.

[20] Höglund, L. and Ågren, J., "Analysis of the Kirkendall effect, marker migration and pore formation", Acta Materialia, Vol. 49, pp. 1311-1317, 2001.

[21] Austin, A.E. and Richard, N.A., "Grain-Boundary Diffusion", Journal of Applied Physics, Vol. 32(8), pp. 1462-1471, 1961.

[22] Rabkin, E., Klinger, L., Izyumova, T. and Semenov, V.N., "Diffusion-induced grain boundary porosity in NiAl", Scripta Materialia, Vol. 42(11), pp. 1031-1037, 2000.

[23] Kolobov, Y.R., Grabovetskaya, G.P., Ratochka, I.V., Kabanova, E.V., Naidenkin, E.V. and Lowe, T.C., "Effect of Grain-Boundary Diffusion Fluxes of Copper on the Acceleration of Creep in Submicrocrystalline Nickel", Annales de Chimie Françaises, Vol. 21, pp. 483-491, 1996.

[24] Philibert, J., Atom movements - diffusion and mass transport in solids, Les Éditions de la Physique, Les Ulis, France, 1996.

[25] Mehrer, H., "The Effect of Pressure on Diffusion", in: Beke, D.L. and Szabó, I.A. Eds., Proceedings of the $1^{\text {st }}$ International Workshop on Diffusion and Stresses, Balatonfüred, Hungary, Defect and Diffusion Forum, Vol. 129-130, pp. 57-74, Scitec Publications, Switzerland, 1996.

[26] Aziz, M., "Thermodynamics of diffusion under pressure and stress: Relation to point defect mechanism", Applied Physics Letters, Vol. 70(21), pp. 2810-2812, 1997.

[27] Tökei, Z., "Effet de la composition chimique et de l'ordre atomique sur la diffusion volumique et intergranulaire dans le cuivre et les composés $\mathrm{Fe}_{3} \mathrm{Al}$ et $\mathrm{FeCo",} \mathrm{Ph.D.} \mathrm{Thesis,} \mathrm{University} \mathrm{of}$ Aix-Marseille, France, 1997 (in French).

[28] Philibert, J., "Influence des contraintes sur les processus de diffusion à l'état solide", Proceedings of Colloque National MECAMAT, Aussois, France, pp. 46-49, 1999 (in French).

[29] Balandina, N., Bokstein, B., Peteline, A. and Ostrovsky, A., "Stresses Effect on Grain Boundary Diffusion in Thin Films", in: Beke, D.L. and Szabó, I.A. Eds., Proceedings of the $1^{\text {st }}$ International Workshop on Diffusion and Stresses, Balatonfüred, Hungary, Vol. 129-130, pp. 151-162, Scitec Publications, Switzerland, 1996. 
[30] Klugkist, P., Aleshin, A.N., Lojkowski, W., Shvindlerman, L.S., Gust, W. and Mittemeijer, E.J., "Pressure and Orientation Dependence of Zn Diffusion along < $001>$ Tilt Grain Boundaries in Al Bicrystals", in: Limoge, Y. and Bocquet, J.L. Eds., International Conference on Diffusion in Materials - DIMAT 2000, Paris, France, Defect and Diffusion Forum, Vol. 194-199, pp. 1153-1160, Scitec Publications, Switzerland, 2001.

[31] Larché, F.C. and Cahn, J.W., "Thermomechanical equilibrium of multiphase solids under stress", Acta Metallurgica, Vol. 26, pp. 1579-1589, 1978.

[32] Larché, F.C. and Cahn, J.W., "The interactions of composition and stress in crystalline solids", Acta Metallurgica, Vol. 33(3), pp. 331-357, 1985.

[33] Larché, F.C. and Voorhees, P.W., in: Beke, D.L. and Szabó, I.A. Eds., Proceedings of the $1^{\text {st }}$ International Workshop on Diffusion and Stresses, Balatonfüred, Hungary, "Diffusion and Stresses: Basic Thermodynamics", Defect and Diffusion Forum, Vol. 129-130, pp. 31-36, Scitec Publications, Switzerland, 1996.

[34] Gorsky, W.S., "Theorie der Elastichen Nachwirkung in Ungeordneten Mischkristallen (Elastische Narchwirkung Zweiter Art)", Physikalische Zeitschrift der Sowjetunion, Vol. 8, pp. 457-471, 1935.

[35] Quan, G.F., "Experimental Study of Hydrogen Diffusion Behaviors in Stress Fields", Corrosion, Vol. 53(2), pp. 99-102, 1997.

[36] Friedel, J., Dislocations, Chapter XVI: Formation and motion of impurity clouds, Vol. 3, $3^{\text {rd }}$ edition, Pergamon Press, 1964.

[37] Mrani, I., Bénet, J.-C. and Fras, G., "Transport of water in a biconstituant elastic medium", Applied Mechanics Reviews, Special Issue on Mechanics of Swelling, Vol. 48(10), pp. 717-721, 1995.

[38] Mrani, I., Bénet, J.-C., Fras, G. and Zrikem, Z., "Two dimensional simulation of dehydration of a highly deformable gel: moisture content, stress and strain fields", Drying Technology, Vol. 15(9), pp. 2165-2193, 1997.

[39] Nazarov, A.A., "Internal stress effect on grain-boundary diffusion in submicrocrystalline metals", Philosophical Magazine Letters, Vol. 80(4), pp. 221-227, 2000.

[40] Mishin, Y. and Razumovskii, I.M., "A model for diffusion along a moving grain boundary", Acta Metallurgica et Materialia, Vol. 40, pp. 839-845, 1992.

[41] Köppers, M., Mishin, M. and Herzig, C., "Fast diffusion of cobalt along stationary and moving grain boundaries in niobium", Acta Metallurgica et Materialia, Vol. 42(8), pp. 2859-2868, 1993.

[42] Mishin, Y., Herzig, C., Bernardini, J. and Gust, W., "Grain boundary diffusion: Fundamental to recent developments", International Materials Reviews, Vol. 42(4), pp. 155-178, 1997. See also Kaur, I., Mishin, Y. and Gust, W., Fundamentals of Grain and Interphase Boundary Diffusion, $3^{\text {rd }}$ enlarged version, John Wiley and Sons Ltd, Chichester, 1995.

[43] Mishin, Y. and Herzig, C., "Diffusion in fine-grained materials: Theoretical aspects and experimental possibilities", NanoStructured Materials, Vol. 6, pp. 859-862, 1995.

[44] Klinger, L. and Rabkin, E., "Beyond the Fisher model of grain boundary diffusion: effect of structural inhomogeneity in the bulk", Acta Materialia, Vol. 47(3), pp. 725-734, 1999.

[45] Chae, K.W., Hwang, C.S., Kim, D.Y. and Cho, S.J., "Diffusion induced recrystallisation of TiC", Acta Materialia, Vol. 44(5), pp. 1793-1799, 1996. 
[46] Friedel, J., Dislocations - Chapter X: Annealing, polygonization, recrystallisation, grain boundaries, Vol. 3, $3^{\text {rd }}$ edition, Pergamon Press, 1964.

[47] Hall, E.O., "The deformation and ageing of mild steel: III Discussion of results", Proceedings of the Physical Society of London, Vol. B64, pp. 747-753, 1951 and Petch, N.J., "The cleavage strength of polycrystals", Journal of the Iron and Steel Institute, Vol. 174, p. 25, 1953.

[48] Schiøtz, J., Di Tolla, F.D. and Jacobsen, K.W., "Softening of nanocrystalline metals at very small grain sizes", Nature, Vol. 391, pp. 561-563, 1998.

[49] Mc Clintock, F.A., "A criterion for Ductile Fracture by the Growth of Holes", Journal of Applied Mechanics, Vol. 35, pp. 363-371, 1968. See also Tvergaard, V., "Material Failure by Void Growth to Coalescence", Advances in Applied Mechanics Vol. 27, pp. 83-151, 1990.

[50] Sénéchal, L., Private communication, AER, 2001.

[51] Yukawa, S. and Sinnott, M.J., "Grain Boundary Diffusion of Nickel into Copper", Journal of Metals - Transactions AIME, Vol. 203, pp. 996-1002, 1955.

[52] Mackliet, C.A., "Diffusion of Iron, Cobalt and Nickel in Single Crystals of Pure Copper", Physical Review, Vol. 109(6), pp. 1964-1970, 1958.

[53] Ikushima, A., "Diffusion of Nickel in Single Crystals of Copper", Journal of the Physical Society of Japan, Vol. 14, pp. 1636, 1959.

[54] Almazouzi, A., Macht, M.P., Naundorf, V. and Neumann, G., "Diffusion of iron and nickel in single-crystalline copper", Physical Review B, Vol. 54(2), pp. 857-863, 1996.

[55] Thomas, D.E. and Birchenall, C.E., "Concentration Dependence of Diffusion Coefficients in Metallic Solid Solution", Journal of Metals - Transactions AIME, Vol. 194, pp. 867-873, 1952.

[56] Hasaka, M., Morimura, T., Uchiyama, Y., Kondo, S.I., Watanabe, T., Hisatsune, K. and Furuse, T., "Diffusion of Copper, Aluminium and Boron in Nickel", Scripta Metallurgica et Materialia, Vol. 29, pp. 959-962, 1993.

[57] Benhenda, S., "Etude, par microscopie électronique et pas spectrométrie Auger, des revêtements protecteurs du cuivre (Au, Ni, Au/Ni et TiN)", Ph.D. Thesis, University of Aix-Marseille, 1987 (in French).

[58] Trønsdal, G.O. and Sørum, H., "Interdiffusion in $\mathrm{Cu}-\mathrm{Ni}$, Co-Ni, and Co-Cu", Physica Status Solidi, Vol. 4, pp. 493-498, 1964.

[59] Johnson, B.C., Bauer, C.L. and Jordan, A.G., "Mechanism of interdiffusion in copper/nickel thin-film couples", Journal of Applied Physics, Vol. 59(4), pp. 1147-1155, 1986.

[60] Grabovetskaya, G.P., Ratochka, I.V., Kolobov, Y.R. and Puchkareva, L.N., "A Comparative Study of Grain-Boundary Diffusion of Copper in Ultrafine-Grained and Coarse-Grained Nickel", The Physics of Metals and Metallography, Vol. 83(3), pp. 310-313, 1997.

[61] Rabkin, E., "Grain Boundary Interdiffusion in the Case of Concentration-Dependent Grain Boundary Diffusion Coefficient", Interface Science, Vol. 3, pp. 219-226, 1996.

[62] Arnould, O. and Hild, F., "Measurement by EDX of Diffusion Profiles of Ni/Cu Assemblies", Microscopy and Analysis, Vol. 66, pp. 13-15 (European edition), pp. 25-27 (Americas edition), 2000.

[63] Arnould, O. and Hild, F., "EPMA Measurements of Diffusion Profiles at the Submicrometre Scale", Mikrochimica Acta, special issue, $7^{\text {th }}$ European Workshop on Modern Developments and Applications in Microbeam Analysis - EMAS 2001, Tampere, Finland, in press. 
[64] Arnould, O. and Hild, F., "Specific Effects and Deconvolution in Submicrometre EPMA: Application to Binary Diffusion", X-ray Spectrometry, submitted.

[65] Belova, I.V. and Murch, G.E., "Analysis of the Hart Equation in Fine-Grained Material", in: Limoge, Y. and Bocquet, J.L. Eds., International Conference on Diffusion in Materials - DIMAT 2000, Paris, France, Defect and Diffusion Forum, Vol. 194-199, pp. 1223-1226, Scitec Publications, Switzerland, 2001.

[66] Sauer, V.F. and Freise, V., "Diffusion in Binären Gemischen mit Volumenänderung", Zeitschrift für Elektrochemie, Vol. 66(4), pp. 353-363, 1962.

[67] Ugaste, Ü, "Concentration Dependence of Diffusion Coefficients in Binary Metal Systems: Empirical Relationships", in: Limoge, Y. and Bocquet, J.L. Eds., International Conference on Diffusion in Materials - DIMAT 2000, Paris, France, Defect and Diffusion Forum, Vol. 194-199, pp. 157162, Scitec Publications, Switzerland, 2001.

[68] Christensen, R.M. and Lo, K.H., "Solution for effective shear properties in three phase sphere and cylindrical models", Journal of Mechanics and Physics of Solids, Vol. 27, pp. 315-330, 1979. See also Christensen, R.M. and Lo, K.H., "Solution for effective shear properties in three phase sphere and cylindrical models (erratum)", Journal of Mechanics and Physics of Solids, Vol. 34, p. 639,1986 .

[69] Hervé, E. and Zaoui, A., "Modelling the effective behavior of nonlinear matrix-inclusion composites", European Journal of Mechanics - A/Solids, Vol. 9(6), pp. 505-515, 1990.

[70] Rabinovich, A.L., "On the Calculations of Orthotropic Laminated Panels Under Tension, Shear and Bending", Trudy Ministerstvo Aviatsionnoi Promyshlennosti, No. 675, 1948. See also Lekhnitskii, S.G., Theory of Elasticity of an Anisotropic Elastic Body, Mir Publishers, Moscow, 1981.

[71] Miloh, T. and Benveniste, Y., "A generalized self-consistent method for the effective conductivity of composites with ellipsoidal inclusions and cracked bodies", Journal of Applied Physics, Vol. 63(3), pp. 789-796, 1988.

[72] Siboni, G. and Benveniste, Y., "A micro-mechanics model for the effective thermo-mechanical behavior of multiphase composite media", Mechanics of Materials, Vol. 11, pp. 107-122, 1991.

[73] Pélissonnier-Grosjean, C., Jeulin, D., Pottier, L., Fournier, D. and Theorel, A., "Mesoscopic modeling of the intergranular structure of $\mathrm{Y}_{2} \mathrm{O}_{3}$ doped aluminium nitride and application to the prediction of the effective thermal conductivity", Key Engineering Materials, Vol. 132-136, pp. 623-626, 1997.

[74] Jeulin, D., "Probabilistic models of structures", in: Frantzisknosis, G.N. Ed., PROBAMAT-21 ${ }^{\text {st }}$ Century: Probability and Materials, Kluwer Academic Publishers, pp. 233-257, 1998. 